\title{
Progression of Frequency and Lethality of Severe Malaria from 2017 to 2020 in the Pediatric Unit of CHUD-Parakou (Benin)
}

\author{
Honorat Francis Lalya', Alphonse Noudamadjo ${ }^{2}$, Falilatou Agbeille-Mohamed ${ }^{2}$, \\ Mèdétinmè Gérard Kpanidja² ${ }^{2}$ Zinsou Rodrigue Ahodègnon ${ }^{2}$, Julien Didier Adédémy², \\ Joseph Agossou ${ }^{2}$
}

${ }^{1}$ Mother and Child Department, Faculty of Health Sciences, University of Abomey-Calavi, Godomey, Benin

${ }^{2}$ Mother and Child Department, Faculty of Medicine, University of Parakou, Parakou, Benin

Email: ${ }^{*}$ ndama_alphonse@yahoo.fr

How to cite this paper: Lalya, H.F., Noudamadjo, A., Agbeille-Mohamed, F., Kpanidja, M.G., Ahodègnon, Z.R., Adédémy, J.D. and Agossou, J. (2021) Progression of Frequency and Lethality of Severe Malaria from 2017 to 2020 in the Pediatric Unit of CHUD-Parakou (Benin). Open Journal of Pediatrics, 11, 551-558.

https://doi.org/10.4236/ojped.2021.114051

Received: August 22, 2021

Accepted: October 12, 2021

Published: October 15, 2021

Copyright $\odot 2021$ by author(s) and Scientific Research Publishing Inc. This work is licensed under the Creative Commons Attribution International License (CC BY 4.0).

http://creativecommons.org/licenses/by/4.0/

\begin{abstract}
Background: The latest WHO report shows a decline in the performances achieved concerning the fight against malaria since 2017. This research work aimed to investigate the progression of frequency and lethality due to severe malaria from 2017 to 2020 in the pediatric unit of the Borgou University Teaching Hospital in Parakou (CHUD-Parakou). Patients and Methods: This research work is a descriptive and analytical case-control study focused on all the children aged 1 month and more, hospitalized in the pediatric unit of CHUD-Parakou from January 1, 2017, to December 31, 2020. Recruitment criteria were the following: be admitted to hospital during the period specified above; have a usable medical record containing the diagnosis and type of discharge, and the findings of thick smear examination and/or of a rapid diagnostic test. Sampling was complete and takes into account all the medical records of children meeting the inclusion criteria. Epi Info 7.2.2 was the software used to perform data processing. Results: The frequencies of severe malaria in the unit were estimated at $19.89 \%, 22.65 \%, 29.65 \%$ and $27.51 \%$ respectively in 2017 , 2018, 2019 and 2020. Lethality rates varied from $7.76 \%$ to 8.68 from 2017 through 2020. The death risk associated with severe malaria was 3.08 times higher in children suffering from severe acute undernutrition. Conclusion: Despite all the efforts made by the health authorities and the technical and financial partners, the frequency and lethality of severe malaria are increasing in the pediatric unit of the B/A Regional University Teaching Hospital (CHUD-B/A). It is therefore worth investigating the determinants of this situation.
\end{abstract}

\section{Keywords}

Severe Malaria, Children, Frequency, Lethality, Benin 


\section{Introduction}

Malaria is the leading cause of morbidity and mortality among children in Sub-Saharan Africa in the post-neonatal period. The last WHO report indicates decreased performances in the domain of the fight against the malarial scourge since 2017 [1]. The purpose of this research work was to investigate the progression of frequency and lethality due to children's severe malaria in the pediatric unit of CHUD-Parakou from 2017 to 2020.

\section{Patients and Methods}

This research work is a descriptive and analytical case-control study centered on all the children aged 1 month and above, hospitalized in the said pediatric unit from January 1, 2017, to December 31, 2020. Recruitment criteria were the following: be hospitalized during the period specified above, have a usable medical record containing the diagnosis and type of discharge, and the findings of thick smear examination and/or of a rapid diagnostic test (RDT). Child death was the dependent variable, and the independent variables were sociodemographic, clinical and epidemiological. Severe malaria was diagnosed according to the WHO criteria [2] i.e. have a positive thick blood smear or RDT to Plasmodium falciparum with at least one sign of danger or severity. The forms of severe malaria were adopted according to the following definitions:

\subsection{Anemic Form of Severe Malaria}

- Any case of malaria with thick blood smear or RDT positive to Plasmodium falciparum and hemoglobin rate below $5 \mathrm{~g} / \mathrm{dL}$ or hemoglobin rate oscillating between 5 and 7 which required blood transfusion on medical prescription when faced with signs of anemic decompensation.

- Neurological form of severe malaria: any case of malaria with thick smear or RDT positive to Plasmodium falciparum and characterized by a neurological sign other than a coma of more than 30 minutes.

- Anemic and neurological form of severe malaria: any case of malaria with thick smear or RDT positive to Plasmodium falciparum with signs of an anemic form of severe malaria and signs of neurological form.

- Cerebral malaria: any case of malaria with coma extended by 30 minutes or more on appropriate treatment.

The nutritional status has been assessed by searching for the nutritional edema, by determining the weight-for-height score, and by measuring the mid-upper arm circumference (MUAC) in children aged 6 to 59 months following the WHO recommendations [3]. Sampling was complete, thus taking into account all the health records of children meeting the inclusion criteria. Epi-Info 7.2 software enabled the entry and analysis of data. The parameters of central tendency of the quantitative variables were described through the computation of mean values and their standard deviation. As regards qualitative variables, ratios were determined. $\mathrm{Chi}^{2}$ test served to compare proportions and the difference was consi- 
dered as significant for a p-value below 0.05 .

\subsection{Ethical and Professional Considerations}

The authors have adhered to data anonymity and confidentiality. The head of the unit issued authorizations for conducting this study.

\section{Results}

All in all, 11568 children were hospitalized from January 1, 2017, to December 31, 2020. Among those children, 8296 were admitted to the hospital for severe malaria i.e. an overall frequency of $71.71 \%$. Among the children suffering from severe malaria, 3831 were female subjects $(46.18 \%)$ and 4465 male subjects (53.82\%) i.e. a sex ratio of 1.16 . The mean age for children was $34.68 \pm 32.40$ months, with extremes of 1 month and 216 months (18 years). Out of the 7394 cases of severe malaria with documented nutritional status, 5420 (73.30\%) had a good nutritional status and 1974 (26.70\%) suffered from acute malnutrition, including 1266 (64.13\%) suffering from moderate acute malnutrition and 708 (35.87\%) from severe acute malnutrition. Table 1 shows the distribution of children according to age.

\subsection{Forms of Severe Malaria}

The anemic form of severe malaria involved $71.43 \%$ of cases of severe malaria if the mixed forms are taken into account i.e. anemic and neurological form of severe malaria (see Table 2)

Table 1. Distribution of children hospitalized in the CHUD-B/A pediatric unit from January 2017 to December 2020, according to age group in months.

\begin{tabular}{ccc}
\hline & Population size & $\%$ \\
\hline $1-5$ & 697 & 06.03 \\
$6-59$ & 8502 & 73.50 \\
$\geq 60$ & 2369 & 20.48 \\
Total & 11,568 & 100.00
\end{tabular}

Table 2. Distribution of children hospitalized in the CHUD-B/A pediatric unit from January 2017 to December 2020 according to the forms of severe malaria.

\begin{tabular}{ccc}
\hline & Number of subjects & $\%$ \\
\hline Anemic form of severe malaria & 3753 & 45.24 \\
Neurological form of severe malaria & 993 & 11.97 \\
Anemic and neurological form of severe malaria & 2173 & 26.19 \\
Cerebral malaria & 208 & 2.51 \\
Other forms of severe malaria & 1169 & 14.09 \\
Total & $\mathbf{8 2 9 6}$ & $\mathbf{1 0 0 . 0 0}$
\end{tabular}




\subsection{Overall Lethality}

Among those children, 695 died, i.e. a lethality rate of $08.38 \%$. Figure 1 and Figure 2 show how distributed the frequency of severe malaria cases and lethality were distributed respectively according to age groups and years.

\subsection{Lethality and Nutritional Status}

Considering the overall acute malnutrition, out of the 1974 severe malaria cases affected by acute malnutrition, there were 193 deaths (09.78\%) versus 412 deaths for 7394 children with good nutritional status (05.57\%); $\mathrm{p}=0.0001$; $\mathrm{OR}=1.83$; $\mathrm{CI}=[1.53-2.19]$.

Table 3 shows the relationship between nutritional status and death in children hospitalized for severe malaria.

\section{Discussion}

This case-control study had some shortfalls in terms of missing data, particularly

\section{Ratio (\%)}

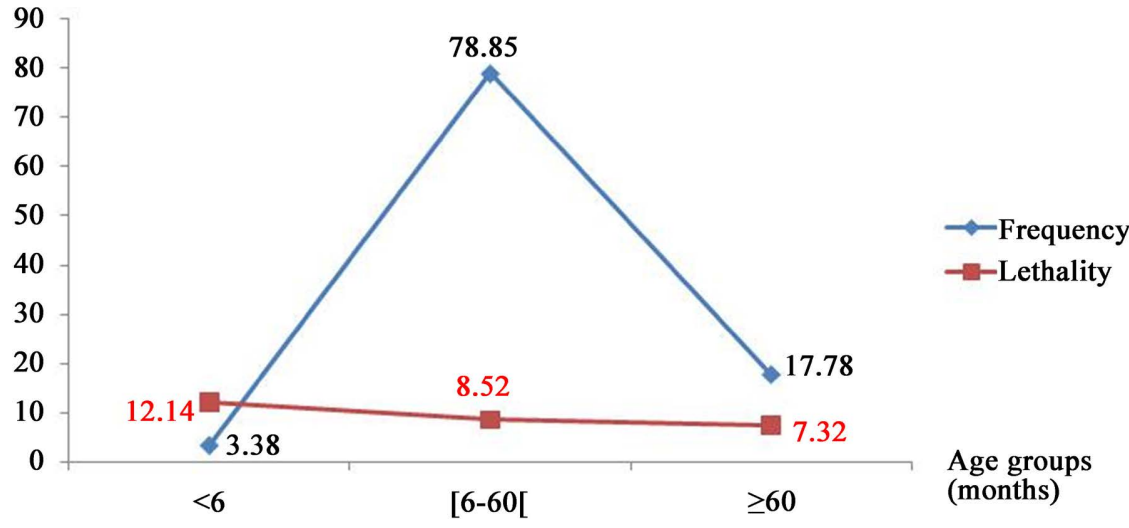

Figure 1. Distribution of cases of severe malaria and lethality by age group in the CHUD-B/A pediatric unit from January 1, 2017, to December 31, 2020.

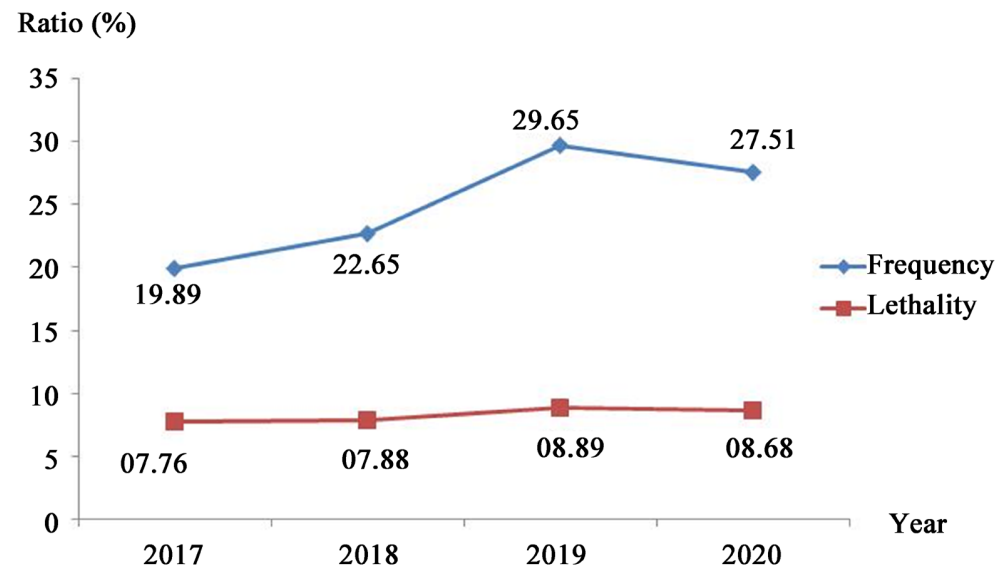

Figure 2. Progression of frequency and lethality of severe malaria in children aged 1 month and more hospitalized in the CHUD-B/A pediatric unit from January 1, 2017, to December 31, 2020. 
Table 3. Relationship between nutritional status and death of children hospitalized for severe malaria in the CHUD-B/A Pediatric Unit from January 1, 2017, to December 31, 2020 .

\begin{tabular}{cccccccccc}
\hline & \multicolumn{8}{c}{ Death } \\
\cline { 2 - 9 } & \multicolumn{7}{c}{ Yes } & \multicolumn{7}{c}{ No } \\
\cline { 2 - 10 } & Total & $\mathbf{n}$ & $\%$ & $\mathrm{n}$ & $\%$ & OR & CI $_{95 \%}$ & p \\
\hline $\begin{array}{c}\text { Nutritional status } \\
\text { Good status }\end{array}$ & 7394 & 412 & 05.57 & 6982 & 94.43 & 1 & & \\
$\begin{array}{c}\text { Moderate acute } \\
\text { malnutrition }\end{array}$ & 1266 & 84 & 06.63 & 1182 & 93.37 & 1.20 & {$[1.02-1.53]$} \\
$\begin{array}{c}\text { Severe acute } \\
\text { malnutrition }\end{array}$ & 708 & 109 & 15.39 & 599 & 84.61 & 3.08 & {$[2.46-3.86]$} \\
\hline
\end{tabular}

concerning the outcome of nutritional status. However, it enabled us to give an account of the current progression of severe malaria cases in the pediatric ward in terms of frequency and lethality, especially in the case of co-morbidity with undernutrition.

\subsection{On the Progression of Frequency}

The study has pointed out that the frequency of severe malaria cases has increased over the years. This may reflect the general situation in the community where environmental degradation and its consequent outbreak of mosquitoes, and parents' economic precarity resulting in children's poor feeding and poor protection, could lead to an upsurge of cases of severe malaria. And as so well illustrated in Figure 1, children aged 6 to 60 months were the most concerned. This may be due, on the one hand, to protection by maternal antibodies before 6 months of age, against the risk of developing malaria, and on the other hand to the acquisition of relative immunity in children over 5 years. In all cases, there is a lot of indication that the use of mosquito nets and other means currently available in households to protect children against mosquito bites is not sufficient. Old and recent similar data on frequencies have been reported by several authors' in Sub-Saharan Africa. For instance, Moyen et al. in Congo in 1993, Camara et al. in 2003 in Senegal, Tchokoteu et al. in Cameroon in 2005, Camara et al. in 2011 in Senegal, Ezeonwu et al. in Nigeria in 2014, Okoko et al. in Congo in 2016, Djadou et al. in Togo in 2017 and Mutombo et al. in Democratic Republic of Congo (DRC) in 2018 have reported respectively 37\%, 16\%, 6.4\%, $30.3 \%, 8.02 \%, 21.05 \%$ and $14.6 \%$ [4]-[11].

\subsection{On the Progression of Lethality}

According to the findings of this study, the trend in lethality due to malaria among children is the same as the one of frequency. This situation may be due to the lack of equipment and inputs necessary for the management of cases of the disease most commonly suffered by the populations. Even though malaria is the 
disease most known by the specialists, the latter may be facing a shortage of the most basic essential drugs to solve the emergency cases generated by this scourge. In addition, the problem of shortage of labile blood products is recurring despite the goodwill of authorities at various levels knowing that, the first form of severe malaria is the anemic one with up to $50.48 \%$ (927) cases of anemic severe malaria out of 1838 cases of severe malaria in all, according to Adédémy et al. in Parakou (Benin) [12]. When considering the age structure of dead children it is noted in Figure 1 that lethality is higher in infants under six months of age and in children above 5 years compared to those aged 6 to 60 months. Regarding infants under 6 months, lethality may result from the immaturity of their defense system but concerning children above five years who in theory have acquired a relative immunity, this result is difficult to explain, thus opening an avenue for research on the factors associated with the death of grown children suffering from severe malaria. The lethality rates reported by African authors were the following: 0.6\% by Moyen et al. in Brazzaville in 1993 [4], 6.5\% by Okoko et al. in 2016 in Brazzaville [9], 4.25\% by Agbeko et al. in Sokodé (Togo) in 2017 [13], 14.5\% in Senegal in 2003 [5], 11.1\% by Camara et al. in Senegal in 2011 [7] and 28.32\% by Mutombo in 2018 in DRC [11].

\subsection{Lethality and Nutritional Status}

The results show that one out of four children suffering from severe malaria had acute malnutrition. The meaning of that association is difficult to discern knowing that, according to the conceptual framework of the causes of malnutrition developed by UNICEF, infections, including chronic parasitic infections, are all part of the immediate causes of acute malnutrition [14]. In the same way, the Plasmodium falciparum would find breeding grounds in an undernourished body. It is therefore a very morbid association. This is all the more true as the relationship between nutritional status and lethality is expressly shown in this research work with a death risk 3.08 times higher in the case of association of severe malaria and severe acute malnutrition. In two publications in 1993 and 2001, authors had reported that more than half of children under 5 years would have not died if they had not been malnourished [15] [16]. As a result, the fight against malaria also consists in improving children's nutritional status.

\section{Conclusion}

Despite all the efforts undertaken by the health authorities and the technical and financial partners, the frequency and lethality of severe malaria are on the rise in the CHUD-B/A pediatric unit. It is necessary to reinforce means and resources for case management on the one hand and to investigate the determinants of that situation on the other hand.

\section{Conflicts of Interest}

The authors declare no conflicts of interest regarding the publication of this pa- 
per.

\section{References}

[1] World Health Organization (2018) World Malaria Report 2018. World Health Organization, Geneva. https://www.who.int/publications/i/item/9789241565653

[2] World Health Organization (2013) Management of Severe Malaria: A Practical Handbook. 3rd Edition, World Health Organization, Geneva. https://apps.who.int/iris/bitstream/handle/10665/79317/9789241548526_eng.pdf

[3] World Health Organization (2013) Guideline: Updates on the Management of Severe Acute Malnutrition in Infants and Children. World Health Organization, Geneva. https://apps.who.int/iris/bitstream/handle/10665/95584/9789241506328_eng.pdf

[4] Moyen, G., Nzingoula, S., Mowandza-Ndinga, J.C., Nkoua, J.L., Mpemba, A.B. and Fourcade, V. (1993) Childhood Malaria in a Pediatric Ward in Brazzaville about 1073 Observations. Médecine d Afrique Noire, 40, 177-181. http://www.santetropicale.com/sites_pays/resume_oa.asp?revue=man\&action=lire\& id_article $=1704 \&$ rep $=$ congo\#close

[5] Camara, B., Diouf, S., Diagne, I., Fall, L., Bamba, A., Sow, D., et al. (2003) Severe Malaria among Children in Senegalese Hospitals. Médecine et maladies infectieuses, 33, 45-48. https://doi.org/10.1016/S0399-077X(02)00014-8

[6] Tchokoteu, P.F., Bitchong-Ekono, C., Tietche, F., Tapko, J.B., Same Ekobo, A., Douala-Mouteng, V., et al. (1999) The Severe Forms of Childhood Malaria in General Pediatric Ward in Yaoundé, Cameroun. Bulletin de la Société de Pathologie Exotique, 92, 153-156.

https://pathexo.societe-mtsi.fr/documents/articles-bull/T92-3-2005.pdf

[7] Camara, B., Diagne/Gueye, N.R., Faye, P.M., Fall, M.L., Ndiaye, J.L., Ba, M., et al. (2003) Severity Criteria and Prognostic Factors of Malaria among Children in Dakar. Médecine et Maladies Infectieuses, 41, 63-67.

https://doi.org/10.1016/j.medmal.2010.09.001 https://www.researchgate.net/publication/251591972

[8] Ezeonwu, B.U., Chima, O.U., Oguonu, T., Ikefuna, A.A.N. and Nwafor, I. (2014) Morbidity and Mortality Pattern of Childhood Illness Seen at the Children Emergency Unit of Federal Medical Center, Asaba, Nigeria. Annals of Medical and Health Science Research, 4, S239-S244.

[9] Okoko, A.R., Angouma Oya, S.M., Moyen, J., Kambourou, J., Ekouya Bowassa, G., Atanda, L., et al. (2016) Childhood Severe Malaria in the University Teaching Hospital of Brazzaville. Journal of Pediatrics and Child Care, 29, 304-306. https://doi.org/10.1016/j.jpp.2016.09.004

[10] Djadou, K.E., Takassi, E.O., Guédénon, J.K. and Atakouma, Y.D. (2017) Severe Malaria in Children at Tsevie Hospital (Togo). International Rural and Elderly Health Informatics Conference (IREHIC), Lomé, 13-17 December 2017, 1-4. https://doi.org/10.1109/IREEHI.2017.8350468

[11] Mutombo, A.M., Mukuku, O., Tshibanda, K.N., Swana, E.K., Mukomena, E., Ngwej, D.T., et al. (2018) Severe Malaria and Death Risk Factors among Children under 5 Years at Jason Sendwe Hospital in Democratic Republic of Congo. Pan African Medical Journal, 29, Article No. 184.

https://doi.org/10.11604/pamj.2018.29.184.15235

http://www.panafrican-med-journal.com/content/article/29/184/full 
[12] Adedemy, J.D., Agossou, J., Alao, M.J., Noudamadjo, A. andAyivi, B. (2015) Role of Severe Anemia and Hypoglycemia in the Mortality of Childhood Severe Malaria in a Hospital Setting of Parakou (Benin). Mali Medical, 30, 19-24.

http://www.revues.ml/index.php/malimed/article/view/587 Consulté le 15/9/2019

[13] Agbeko, F., Takassi, O.E., Fiawoo, M., Guedehoussou, T., Dossou, F., Segbedji, K.A.R., et al. (2017) In-Hospital Mortality in the Pediatric Unit of the Regional University Teaching Hospital of Sokodé (Togo) in 2015. Journal of Scientific Research of the University of Lomé, 19, 297-302.

https://www.ajol.info/index.php/jrsul/article/view/167587

[14] UNICEF (United Nations Children's Fund) (1998) The State of the World's Children.

https://www.unicef.org/sowc/archive/ENGLISH/The\%20State\%20of\%20the\%20Wo rld\%27s\%20Children\%201998.pdf

[15] Pelletier, D.L., Frongillo, E.A. and Habicht, J.-P. (1993) Epidemiologic Evidence for a Potentiating Effect of Malnutrition on Mortality. American Journal of Public Health, 83, 1130-1133. https://doi.org/10.2105/AJPH.83.8.1130

https://www.researchgate.net/publication/14856022_Epidemiologic_evidence_for_a _potentiating_effect_of_malnutrition_on_mortality

[16] Rice, A.L., Sacco, L., Hyder, A. and Black, R.E. (2001) Malnutrition as the Subjacent: Cause of Child Death by Infectious Diseases in Developing Countries. Bulletin of the World Health Organization, Collection of Articles No. 4, 97-110.

https://apps.who.int/iris/bitstream/handle/10665/74843/RA_2001_4_97-110_fre.pdf ?sequence $=1$ 